\title{
INFLUENCE OF READING HABITS ON CEREBRAL PLASTICITY FOR DISCOURSE COMPREHENSION IN AGING
}

Charles-Olivier Martin Université de Montréal Institut universitaire de gériatrie de Montréal

Marianne Desrochers Université de Montréal Institut universitaire de gériatrie de Montréal

Catrine Demers Université de Montréal Institut universitaire de gériatrie de Montréal

Lilian Cristine Scherer Pontifícia Universidade Católica do Rio Grande do Sul

Bernadette Ska

Université de Montréal Institut universitaire de gériatrie de Montréal

\begin{tabular}{|l|l|l|l|l|}
\hline Ilha do Desterro & Florianópolis & n 63 & p. 101-127 & jul/dez 2012 \\
\hline
\end{tabular}


102 Charles-Olivier Martin et al., Influence of reading habits on cerebral...

\begin{abstract}
The goal of this study was to evaluate the influence of reading habits on cerebral plasticity in the performance of a discourse comprehension task in aging. The main hypothesis was that participants with higher frequency and quality of reading habits should exhibit reduced brain activity because the task should be easier for them. Two groups of native French speakers, 16 young adults and 16 elderly adults, participated in a task using the NIRS (near-infrared spectroscopy) technique. They read short stories and answered true or false probes after each one. They also completed a questionnaire about their previous reading habits. The results show that the more experienced readers had higher activation in the superior left region of the prefrontal cortex while they were reading the stories but lower activation in the same region when they were retrieving the information to answer the probe. Thus, more effort is required to acquire and maintain the information needed to answer, and this effort makes it easier to give the answer. These results reinforce the hypothesis that brain plasticity is promoted by cognitive activities throughout the lifespan.
\end{abstract}

\title{
Introduction
}

Discourse, in both the oral and written modality, is the basis of human communication. Discourse comprehension, which may appear to be an automatic component of language, is actually very complex from the perspective of cerebral functioning. Like other components of cognition, discourse comprehension changes with aging. The goal of this study is to evaluate the influence of reading habits on discourse comprehension mechanisms in the aging brain. 


\section{Discourse comprehension}

To understand a text, it is necessary to build a mental representation based on previous linguistic and conceptual knowledge and on the elements of the text (Kintsch, 1988). Discourse comprehension is strongly linked to many cognitive functions such as working memory, long-term memory, information processing and inference drawing (Chesneau, Jbabdi, Champagne-Lavau, Giroux, \& Ska, 2007).

According to Kintsch's (1988) model, comprehension requires four levels of representation: linguistic level, textbase or conceptual level, structure, and situation model. This study will consider the textbase and situation model levels.

The textbase model comprises the whole set of semantic propositions or semantic units. There are two types of propositions: micropropositions and macropropositions. Micropropositions refer to all the details of a text, reflecting local information in the text, while macropropositions refer to the global information contained in the text (Kintsch \& van Dijk, 1978).

The situation model is a mental construction generated by the integration of information in the text with the reader's acquired knowledge (Radvansky, 1999). It is the result of inferences about characters, actions and events described in the text (Radvansky, Zwaan, Curiel, \& Copeland, 2001; Van Dijk \& Kintsch, 1983). This mental construction of a model leads to text comprehension (Radvansky \& Dijkstra, 2007).

In the construction-integration model (Kintsch, 1988), propositionsfirstenter short-term memory. Then, theyare reorganized or replaced by new entries and integrated into the proposition network. This network is updated at each new comprehension cycle. Thus, the 
textbase level depends mainly on short-term memory. The situation model is built at the end of each construction-integration cycle from this small network of propositions. The temporary situation model is then placed in episodic memory (Chesneau, 2007). However, knowledge stored in the reader's long-term memory may interfere with the information in the situation model. On the other hand, the global coherence of a text is supported by long-term working memory, which maintains information retrieval and processing (Ericsson \& Kintsch, 1995). Consequently, the situation model is the result of a complex interaction between working memory, episodic memory, long-term memory and long-term working memory.

\section{Cerebral plasticity}

Aging is a process that modifies cognitive functioning, especially memory, executive functions and processing speed (Craik \& Salthouse, 2000; Salthouse, 1996). However, the aging effect is not homogeneous and inter-subject and inter-function differences may appear. The brain has a capacity to adapt, which makes it able to overcome a partial loss of cognitive efficiency caused by lesions or aging. For example, some patients suffering from aphasia recover almost all of their language capacity because of the increased involvement of the right hemisphere in language processing, the recruitment of new networks in the left hemisphere, and the partial repair of damaged networks (Cao, Vikingstad, George, Johnson, \& Welch, 1999). Many models, such as the HAROLD (Hemispheric Asymmetry Reduction in Older Adults) model (Cabeza, 2002) and the PASA (Posterior-Anterior Shift in Aging) model (Davis, Dennis, Daselaar, Fleck, \& Cabeza, 2008), and theories such as cognitive reserve (Stern, 2002) and the Scaffolding Theory of Aging and 
Cognition (STAC) (Park \& Reuter-Lorenz, 2009), try to explain how the brain adapts to the challenge of lesions or aging.

The cognitive reserve theory deals with the incongruity often observed between the degree of brain damage and its clinical manifestations (Stern, 2009). Depending on their cognitive reserve, among other factors, two patients with the same cerebral lesions or pathology may not demonstrate the same cognitive loss. Similarly, two elderly adults will age differently, retaining different cognitive abilities. The cognitive reserve theory suggests that the brain actively compensates for lesions. Therefore, when cerebral networks usually dedicated to a particular task are damaged, the brain compensates by using other available networks not usually used for that specific task (Stern, 2002).

These networks are built and maintained throughout the lifespan. They are highly influenced by education level, occupation, intelligence, and leisure activities that stimulate cognition (SolePadulles et al., 2009). In fact, cognition stimulated by leisure activities may have protective effects by decreasing the atrophy of certain brain regions, even if they are started at an advanced age (Jones et al., 2010).

The STAC theory describes scaffolding as a normal process, through the lifespan, involving the development or use of complementary or alternative neural circuits to compensate for certain aging effects (Park \& Reuter-Lorenz, 2009). The major difference between the cognitive reserve theory and the STAC is that cognitive reserve prevents cognitive losses, while scaffolding seems to be a response to those losses. The scaffolding theory describes the brain's ability to build new networks when the usual ones are impaired.

Many factors facilitate the building of new networks in aging. Among other things, training (Fincham \& Anderson, 2006; Wolinsky 
et al., 2010), physical activities (Lemaire \& Bherer, 2005) and leisure activities (Sole-Padulles et al., 2009) may enhance performance in aging, even on tasks that depend on memory and executive functions.

\section{Reading habits}

Reading is considered to be an intellectual activity that contributes to building cognitive reserve or scaffolding support. However, it has mainly been studied as a type of leisure activity that could have a beneficial effect on cerebral plasticity in aging. In fact, reading may have several goals, but here we will consider reading for any purpose. In this study, reading was considered separately from other activities since it may have a greater effect on language tasks such as discourse comprehension because it is dependent on language. Moreover, the importance of reading habits for cognitive development and maintenance, as well as to retard neuropsychological aging, which may develop into mild cognitive impairment or dementia, is now well established in the literature (Parente, Fonseca, \& Scherer, 2008; Schaie, 2008). A study with a group of subjects aged more than 65 years old concludes that reading habits are a protective factor against cognitive impairment, such as dementia, and that this protective effect is greater in frequent readers, as shown by a logistic regression (Esteve \& Gil, 2012). Despite those proofs of the importance of reading habits in healthy aging, no studies had previously investigated their influence on brain activity.

\section{NIRS}

The present study uses the Near-Infrared Spectroscopy (NIRS) technique. Near-infrared light penetrates organic tissues without being 
absorbed in the range of 680 to $1000 \mathrm{~nm}$ (Gratton \& Fabiani, 2007). The NIRS technique measures hemodynamic changes in the brain by looking at the variation in concentration of two chromophores (lightabsorbing molecules): oxyhemoglobin $(\mathrm{O} 2 \mathrm{Hb})$ and deoxyhemoglobin (HHb) (Hoshi, 2007). Their respective concentrations are calculated by interpreting the quantity of light detected at the exit from the head with the modified Beer-Lambert Law. The changes in light detection match the changes in the concentration of these chromophores, because the light ray's diffusion in the tissue is considered to be constant (Strangman, Boas, \& Sutton, 2002).

\section{Goal and hypotheses}

The goal of this study is to evaluate the influence of reading habits on cerebral plasticity, as assessed by NIRS, during a discourse comprehension task. Four hypotheses underlie the study. First, participants with stronger reading habits in terms of quantity and quality should get better results when evaluating the situation model but the same results for micropropositions and macropropositions as readers with weaker reading habits. Indeed, the situation model calls for more in-depth information processing, linked to episodic and semantic memory, while the textbase depends more on shortterm memory (Chesneau, 2007). Stronger reading habits should have a greater training effect when a higher level of comprehension is needed. The second hypothesis made in this study was that participants with stronger reading habits should have faster reaction times because training should speed up the retrieval of information, as it does in the case of other cognitive functions (Wolinsky et al., 2010). Third, participants with stronger reading habits should show less cerebral activity because the task should be easier for them due 
to the training effect (Fincham \& Anderson, 2006). This decrease due to practice has been found in many cognitive tasks, especially ones referring to working memory (Kelly \& Garavan, 2005). Fourth, given that reading habits are considered as contributing to cognitive reserve, and thus helping to reduce the cognitive decline in aging, the effects of strong reading habits should be more evident in the elderly group. Thus, greater correlations between reading habits and brain activity should be observed in this group (Stern, 2009).

\section{Method}

\section{Participants}

Thirty-two adults participated in this study: 16 elderly adults, from 62 to 75 years old, and 16 young adults, from 20 to 25 years old. All had university degrees (15 to 21 years of education). All were right-handed, as assessed by the Edinburgh Handedness Inventory (Oldfield, 1971) with a score of 80 or higher; had French as their mother tongue; and had normal or corrected vision. They did not have dyslexia, diabetes, psychiatric or neurological impairments, or a history of alcoholism or drug addiction.

All elderly participants had a score of 27 or more on the MiniMental State Evaluation (MMSE) (Folstein, Folstein, \& McHugh, 1975). No participant had impaired cognitive functions such as attention (Trail Making Test, parts A and B) (Reitan \& Wolfson, 1985), inhibitory control (Stroop Victoria Test) (Stroop, 1935), short-term and long-term memory (Buschke Selective Reminding Test) (Buschke, 1973), working memory (Digit Span test) (Wecksler, 1991), and mental flexibility (Wisconsin Cart Sorting Test, 64-card version) (Nelson, 1976). These data are displayed in Table I. 
Table I. Characteristics of the participants

\begin{tabular}{|c|c|c|}
\hline & $\begin{array}{l}\text { Younger group } \\
10 \text { women; } 6 \\
\text { men } \\
M(S D)\end{array}$ & $\begin{array}{l}\text { Older group } \\
14 \text { women; } 2 \text { men } \\
M(S D)\end{array}$ \\
\hline $\operatorname{Age}^{* *}$ & $22.4(2.7)$ & $68.0(4.1)$ \\
\hline Education & $16.3(1.7)$ & $17.3(2.1)$ \\
\hline MMSE & $\mathrm{n} / \mathrm{a}$ & $29.3(0.7)$ \\
\hline \multicolumn{3}{|c|}{$\begin{array}{l}\text { Buschke Selective Reminding } \\
\text { test }\end{array}$} \\
\hline Encoding $^{* *}$ & $40.4(2.8)$ & $35.3(5.9)$ \\
\hline Delayed recall ${ }^{\star}$ & $15.2(1.0)$ & $13.7(2.4)$ \\
\hline \multicolumn{3}{|l|}{ Stroop Victoria } \\
\hline $\operatorname{Time}^{* *}$ & $16.2(2.7)$ & $25.9(6.8)$ \\
\hline Errors & 0 & $0.2(0.4)$ \\
\hline \multicolumn{3}{|c|}{ Trail Making Test A \& B } \\
\hline A- Time $e^{* *}$ & $21.9(7.0)$ & $38.1(11.2)$ \\
\hline A- Errors & 0 & 0 \\
\hline B- Time ${ }^{* *}$ & $44.3(12.5)$ & $68.0(24.7)$ \\
\hline B- Errors & $0.1(0.3)$ & $0.1(0.5)$ \\
\hline $\mathrm{B}$ minus $\mathrm{A}$ & $22.4(11.8)$ & $30.9(18.7)$ \\
\hline \multicolumn{3}{|l|}{ Digit Span } \\
\hline Forward & $11.4(1.7)$ & $10.5(2.3)$ \\
\hline Backward & $9.3(2.3)$ & $7.6(2.6)$ \\
\hline \multicolumn{3}{|c|}{ Wisconsin Card Sorting Task } \\
\hline Categories $^{\star *}$ & $4.7(0.6)$ & $3.4(1.4)$ \\
\hline Errors $^{\star *}$ & $9.1(3.9)$ & $17.8(9.9)$ \\
\hline
\end{tabular}




\section{Task}

The task consists of 36 short stories and probes constructed by Scherer et al. (2007). The stories and probes were divided into three blocks evaluating different components of the discourse comprehension model: micropropositions, macropropositions and situation model. Participants had to read a short story (about 3 or 4 sentences) on a computer. Right after that, they had to press a button to indicate whether the presented probe was true or false, according to the short story they had just read. All the stories and probes had been controlled for the number of sentences, words, syllables, numbers and propositions (Scherer et al., 2007). None of the stories and probes contained irony, indirect language or metaphor. Each block lasted 600 seconds (10 minutes), for a total of 30 minutes for the whole task. Each block began after presentation of a fixation cross for 45 seconds. The run then consisted of a short story displayed for 15 seconds; a probe for 5 seconds, when the participants had to answer "true" or "false"; and a fixation cross for 20 seconds. This 40 -second run was repeated 12 times during each block. After that, a fixation cross was presented for 35 seconds and the participants could relax for 60 seconds. The order of the blocks was counterbalanced between the participants.

\section{Questionnaire on reading habits}

In order to establish the participants' reading habits, a questionnaire adapted from Wilson, Barnes, and Bennett (2003) was used. This questionnaire contains items about different aspects of reading (frequency of reading, types of reading, visits to the library, etc.) during five different periods of respondents' life (at 6, 12, 18 and 40 years old and now) (Wilson et al., 2003). The questionnaire uses a scoring scale 
between 1 and 5; 1 represents "less than once a year" and 5 represents "almost every day." The total score for the young adults was 100 . The total score for the elderly adults was 125 , but a percentage was calculated to compare their data to the data from the young adults. The difference is due to the fact that the elderly adults gave answers related to when they were 40 years old, but the young adults could not do this.

\section{Procedure}

The task was performed individually in a dark and silent room in the Centre de Recherche de l'Institut universitaire de gériatrie de Montréal (CRIUGM). The participants were seated on a chair in front of a computer and they had an NIRS headpiece placed on their forehead against the prefrontal cortex. The right index finger was on the location of the letter " $\mathrm{p}$ " and the left index finger on the location of letter " $\mathrm{q}$ " on the keyboard. These keys were covered by a big green "V" (for vrai in French, meaning 'true') and a big red "F" (for faux in French, meaning 'false'). The locations of the " $\mathrm{V}$ " and the " $\mathrm{F}$ " were counterbalanced between the participants. They were asked to read silently and to avoid speaking or moving.

\section{Data acquisition}

The data were acquired using a TechEn CW32 NIRS system on the prefrontal cortex (headpiece placed on the participant's forehead). One source and four detectors were distributed on both left and right hemispheres, for a total of eight source-detector pairs corresponding to eight channels (see Figure 1). The channels covered on Brodmann area (BA) 10 (channels 1, 4, 5 and 6) and BA 46 (channels 2, 3, 7 and 8). Channels 6, 4, 7 and 2 correspond, respectively, to Fp1, Fp2, AF3 
112 Charles-Olivier Martin et al., Influence of reading habits on cerebral...

and AF4 according to the 10/20 international system (Jasper, 1958). The near-infrared light consisted of two wavelengths $(690 \mathrm{~nm}$ and $830 \mathrm{~nm}$ ) to assess the measures of $\mathrm{O} 2 \mathrm{Hb}$ and $\mathrm{HHb}$. The changes in $\mathrm{O} 2 \mathrm{Hb}$ and $\mathrm{HHb}$ concentration were estimated by the general linear model and calculated by the modified Beer-Lambert law.
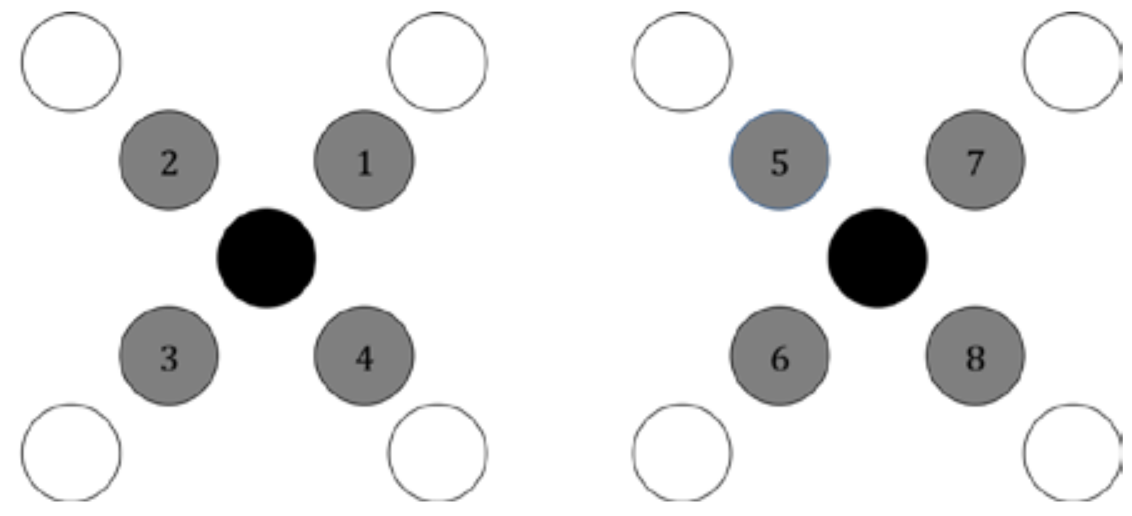

Figure 1. The positioning of the sources (black), detectors (white) and channels (gray).

\section{Statistical analysis}

To investigate the relationship between reading habits and brain function during the processing of the discourse comprehension task, correlation analyses were done (1) between the behavioral data (performance and reaction times in the task) and the scores obtained in the reading habits questionnaire; and (2) between the neuroimaging data (variation in $\mathrm{O} 2 \mathrm{Hb}$ and $\mathrm{HHb}$ during the task) and the scores obtained in the reading habits questionnaire. The correlation analyses were performed separately for each age group. Only the neuroimaging data from trials in which the participant 
gave the right answer were kept, since the study aimed at analyzing correct responses in discourse comprehension. The correlations using Pearson's coefficient were performed by SPSS software 18.0 (Statistical Package for Social Sciences).

\section{Results}

In the questionnaire on their reading habits, the mean score for the young participants was $74 / 100(\mathrm{SD}=7.4)$ and the mean for the elderly participants was 69/100 $(\mathrm{SD}=8.5)$ (see Figure 2).

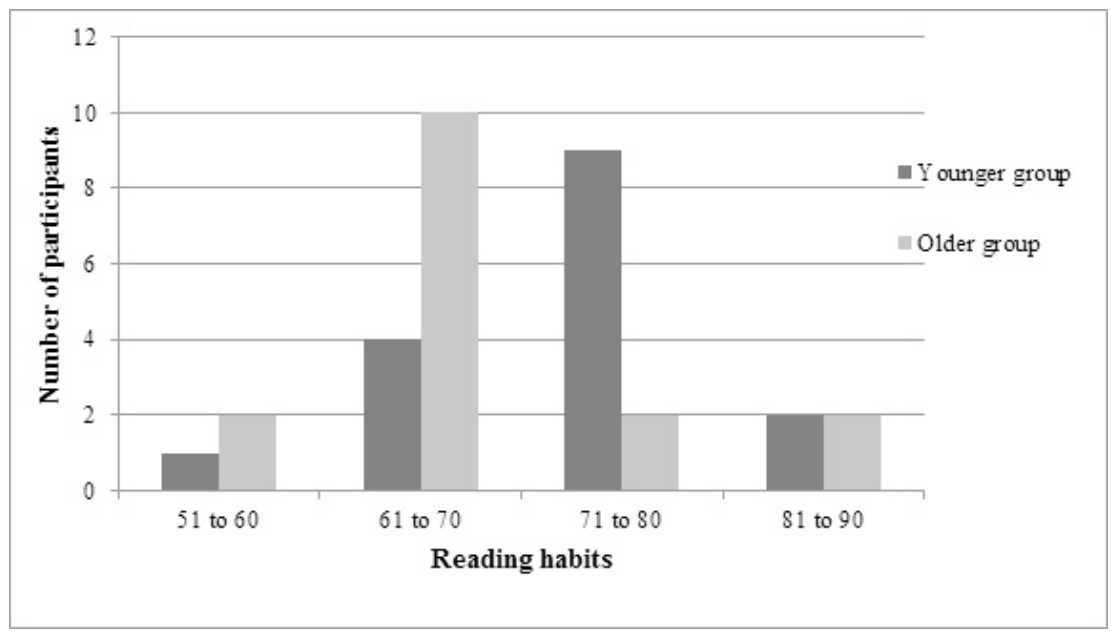

Figure 2. Distribution of the young and elderly participants based on their score out of 100 for the questionnaire on reading habits throughout their lives.

\section{Behavioral data}

This part of the study looks at the possible correlation between reading habits and accuracy of responses (Table II) and between 
114 Charles-Olivier Martin et al., Influence of reading habits on cerebral...

reading habits and reaction times (Table III). The only significant correlation was found between reading habits and accuracy for the situation model in the older group of participants. This correlation shows that participants with the strongest reading habits are the ones who produced the most incorrect answers. There is no significant correlation between reading habits and reaction time. However, there is a tendency in the younger group for participants who read the most to answer faster than the others (Figure 3). This tendency is not present in the older group (Figure 4).

Table II. Pearson's correlation coefficient between the accuracy of responses and scores on the reading habits questionnaire for each condition

\begin{tabular}{lll}
\hline Condition & Younger group & Older group \\
\hline Micropropositions & 0.183 & -0.077 \\
Macropropositions & -0.240 & 0.240 \\
Situation model & 0.464 & $\mathbf{- 0 . 6 1 1 ^ { \star }}$ \\
\hline${ }^{*} p<.05$ &
\end{tabular}

Table III. Pearson's correlation coefficient between reaction times (ms) and scores on the reading habits questionnaire for each condition

Condition $\quad$ Younger group Older group

\begin{tabular}{lll}
\hline Micropropositions & -0.480 & 0.359 \\
Macropropositions & -0.315 & 0.204 \\
Situation model & -0.348 & -0.202 \\
\hline
\end{tabular}




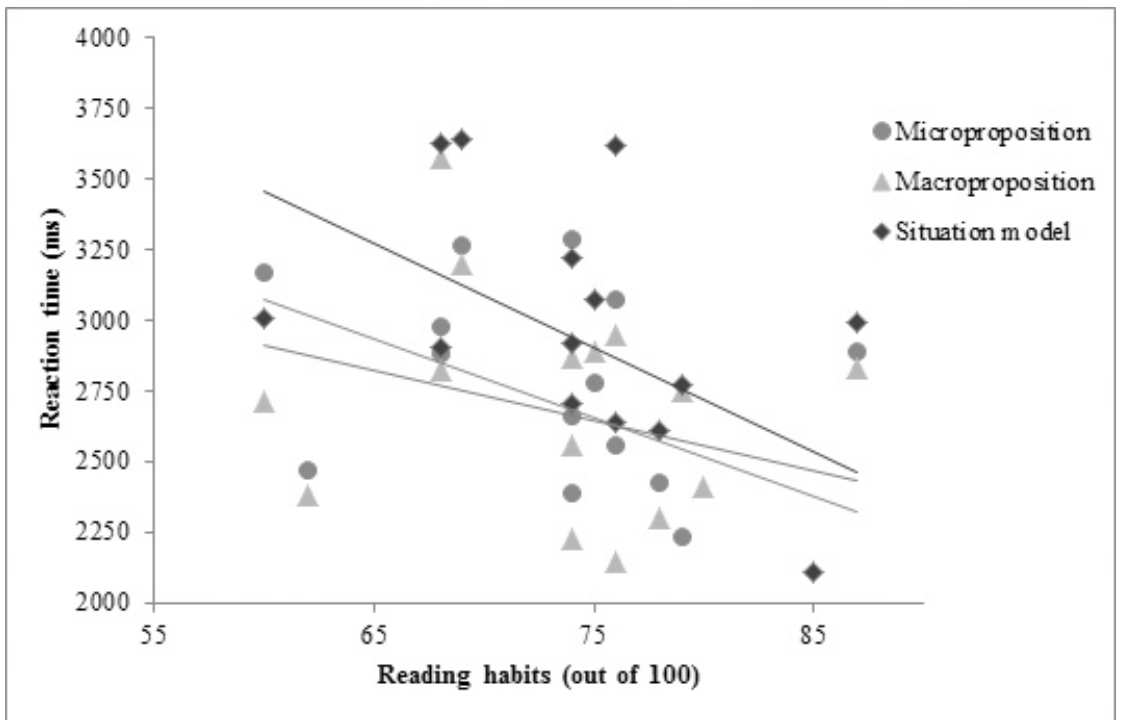

Figure 3. Relationship between scores for reading habits and reaction times in all three conditions for the younger group.

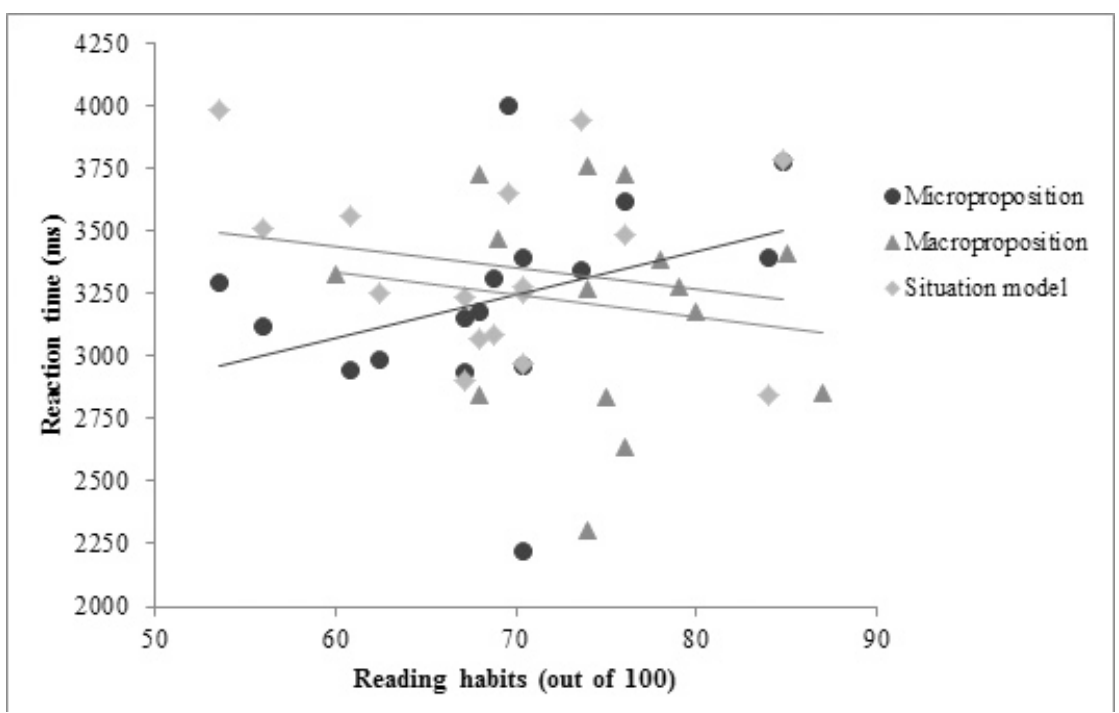

Figure 4. Relationship between scores for reading habits and reaction times in all three conditions for the older group. 


\section{Neuroimaging data}

This part of the study looks at the possible correlation between reading habits and brain activity, as shown by the variation of $\mathrm{O} 2 \mathrm{Hb}$ and $\mathrm{HHb}$ in the prefrontal cortex. Significant correlations were found between reading habits and $\mathrm{O} 2 \mathrm{Hb}$ variation in channels 5 and 7 (refer to Table IV) for the older group. These correlations were found in all three conditions of the discourse comprehension task. Participants with the strongest reading habits experienced more $\mathrm{O} 2 \mathrm{Hb}$ variation than others while they were reading the story, but less $\mathrm{O} 2 \mathrm{Hb}$ variation while they answered the probes (Figures 5 and 6 ). There is no clear pattern of correlation for the younger group; in fact, there is only one significant correlation, between reading habits and brain activity in channel 5 (Table V).

Table IV. Pearson's correlation coefficient between the variation in $\mathrm{O} 2 \mathrm{Hb}$ concentration and scores on the reading habits questionnaire for each channel in each condition in the older group

\begin{tabular}{|c|c|c|c|c|c|c|}
\hline \multirow{2}{*}{ Channels } & \multicolumn{2}{|c|}{ Micropropositions } & \multicolumn{2}{|c|}{ Macropropositions } & \multicolumn{2}{|c|}{ Situation model } \\
\hline & Story & Probe & Story & Probe & Story & Probe \\
\hline 1 & 0.112 & 0.037 & 0.372 & 0.099 & -0.048 & -0.373 \\
\hline 2 & -0.102 & $-0.584^{\star}$ & 0.157 & 0.227 & 0.177 & -0.342 \\
\hline 3 & -0.187 & 0.020 & -0.115 & -0.070 & 0.003 & -0.266 \\
\hline 4 & -0.064 & -0.065 & 0.014 & -0.262 & 0.124 & -0.479 \\
\hline 5 & 0.152 & $-0.720^{\star *}$ & $0.564^{*}$ & $-0.569^{\star}$ & $0.522^{\star}$ & $-0.676^{\star *}$ \\
\hline 6 & -0.308 & 0.080 & -0.269 & -0.151 & 0.210 & -0.330 \\
\hline 7 & 0.220 & $-0.572^{\star}$ & $0.517^{\star}$ & $-0.498^{\star}$ & $0.554^{\star}$ & $-0.676^{* *}$ \\
\hline 8 & -0.068 & -0.184 & -0.060 & -0.195 & 0.166 & -0.476 \\
\hline
\end{tabular}

${ }^{\star} \mathrm{p}<.05 ;{ }^{* *} \mathrm{p}<.01$ 


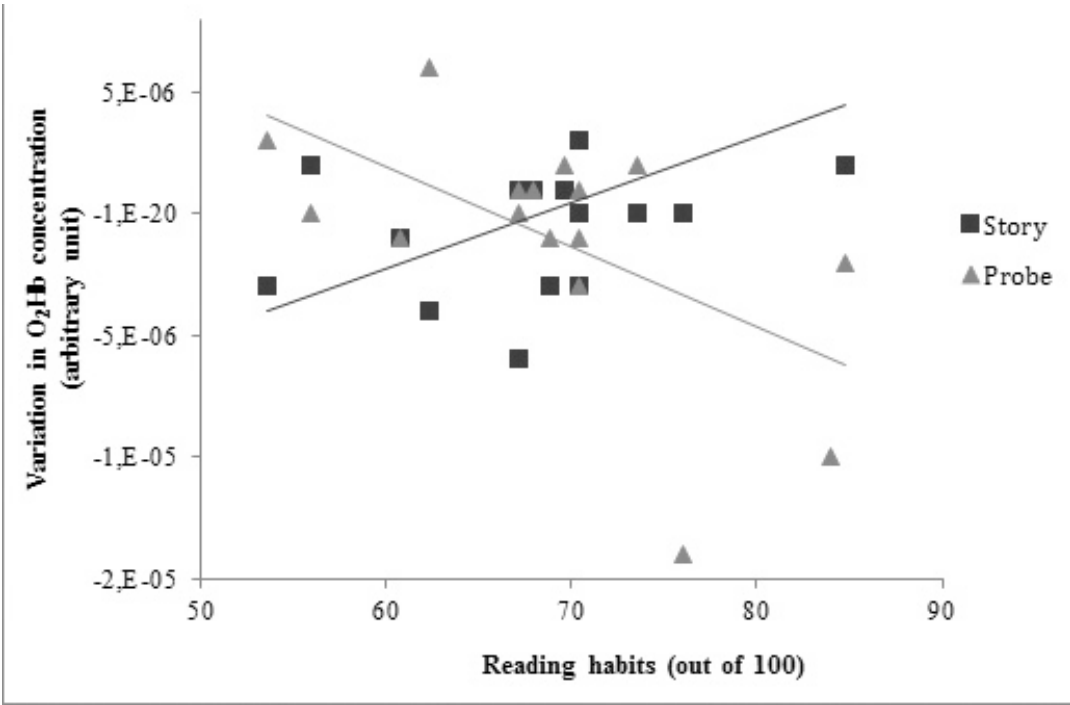

Figure 5. Relationship between the variation in $\mathrm{O} 2 \mathrm{Hb}$ concentration in channel 5 and reading habits for the older group in the microproposition condition while participants read the story $\left(0.564^{\star}\right)$ and answered the probe $\left(-0.569^{\star}\right)$.

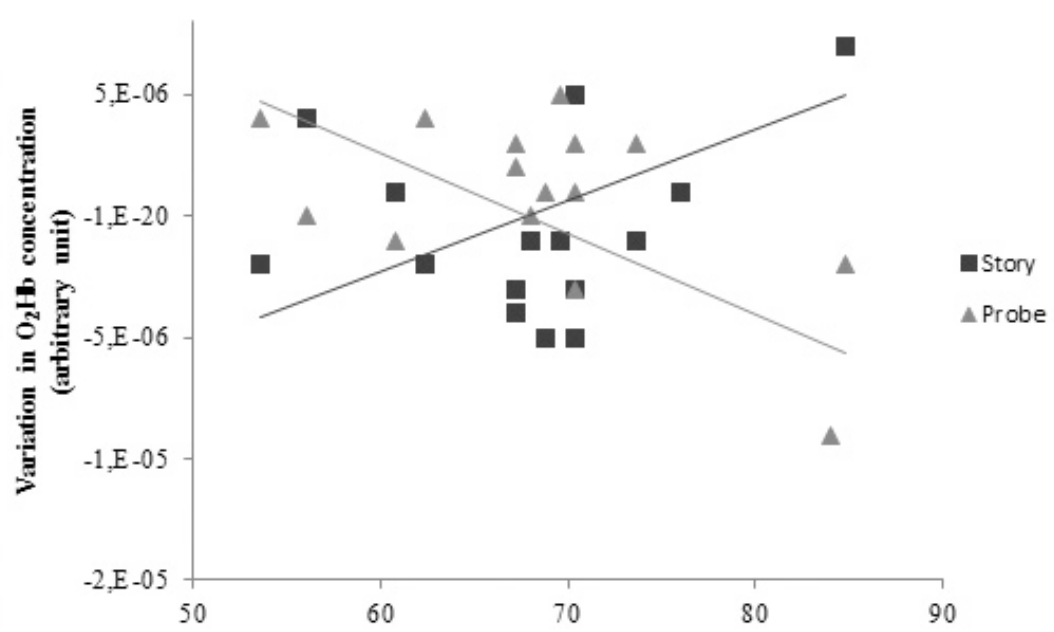

Reading habits (out of 100) 
Figure 6. Relation between the variation in $\mathrm{O} 2 \mathrm{Hb}$ concentration in channel 7 and reading habits for the older group in the microproposition condition while the participants read the story $\left(0.517^{\star}\right)$ and answered the probe $\left(-0.498^{\star}\right)$.

Table V. Pearson's correlation coefficient between the variation in $\mathrm{O} 2 \mathrm{Hb}$ concentration and scores on the reading habits questionnaire for each channel in each condition in the younger group

\begin{tabular}{lllllll}
\hline \multirow{2}{*}{ Channels } & \multicolumn{2}{c}{ Micropropositions } & \multicolumn{2}{c}{ Macropropositions } & \multicolumn{2}{c}{ Situation model } \\
& Story & Probe & Story & Probe & Story & Probe \\
\hline 1 & -0.105 & -0.232 & -0.193 & -0.325 & -0.418 & -0.193 \\
2 & -0.029 & -0.196 & -0.077 & -0.341 & -0.388 & -0.138 \\
3 & -0.065 & 0.325 & -0.450 & -0.192 & -0.479 & -0.040 \\
4 & -0.078 & 0.095 & -0.320 & 0.047 & -0.335 & 0.213 \\
5 & -0.254 & 0.059 & -0.150 & -0.276 & $-\mathbf{0 . 5 0 5}$ & -0.076 \\
6 & -0.143 & 0.184 & -0.256 & -0.047 & -0.226 & 0.030 \\
7 & -0.069 & 0.193 & -0.124 & -0.190 & -0.382 & -0.028 \\
8 & 0.007 & 0.441 & -0.339 & 0.041 & -0.270 & -0.035 \\
\hline $\mathrm{p}<.05$ & & & & & &
\end{tabular}

Few significant correlations appeared between reading habits and $\mathrm{HHb}$ variation in the older group (Table VI). There was no clear pattern for the variation in $\mathrm{HHb}$. In the younger group, there was no significant correlation between reading habits and $\mathrm{HHb}$ variation (Table VII).

Table VI. Pearson's correlation coefficient between the variation in $\mathrm{HHb}$ concentration and scores on the reading habits questionnaire for each channel in each condition in the elderly group 


\begin{tabular}{lllllll}
\hline \multirow{2}{*}{ Channels } & \multicolumn{2}{l}{ Micropropositions } & \multicolumn{2}{l}{ Macropropositions } & \multicolumn{2}{l}{ Situation model } \\
& Story & Probe & Story & Probe & Story & Probe \\
\hline 1 & 0.145 & 0.482 & 0.434 & $\mathbf{0 . 5 4 7}^{\star}$ & 0.063 & 0.270 \\
2 & $\mathbf{0 . 6 2 9 * *}$ & -0.420 & $\mathbf{0 . 6 1 2}$ & $\mathbf{0 . 5 9 1}$ & 0.036 & -0.079 \\
3 & 0.175 & $\mathbf{0 . 6 8 5}$ & -0.155 & 0.382 & 0.012 & -0.030 \\
4 & 0.452 & -0.164 & 0.200 & -0.193 & 0.012 & -0.048 \\
5 & -0.138 & -0.003 & 0.339 & -0.075 & $\mathbf{0 . 5 1 9}$ & -0.462 \\
6 & 0.139 & 0.194 & 0.117 & 0.115 & 0.029 & 0.400 \\
7 & 0.479 & -0.384 & 0.467 & -0.183 & $\mathbf{0 . 5 4 8}$ & $-\mathbf{0 . 5 3 5}$ \\
8 & 0.264 & 0.157 & -0.079 & 0.208 & -0.016 & 0.441 \\
\hline${ }^{\star} \mathrm{p}<.05 ;{ }^{* *} \mathrm{p}<.01$ & & & & &
\end{tabular}

Table VII. Pearson's correlation coefficient between the variation in $\mathrm{HHb}$ concentration and scores on the reading habits questionnaire for each channel in each condition in the younger group

\begin{tabular}{lllllll}
\hline \multirow{2}{*}{ Channels } & \multicolumn{2}{c}{ Micropropositions } & \multicolumn{2}{c}{ Macropropositions } & \multicolumn{2}{c}{ Situation model } \\
& Story & Probe & Story & Probe & Story & Probe \\
\hline 1 & 0.305 & 0.030 & 0.097 & 0.082 & -0.010 & -0.318 \\
2 & -0.021 & 0.301 & -0.269 & 0.169 & -0.126 & -0.027 \\
3 & -0.110 & 0.114 & -0.196 & -0.020 & -0.328 & -0.063 \\
4 & -0.023 & 0.298 & -0.239 & 0.380 & -0.219 & 0.266 \\
5 & 0.074 & -0.081 & -0.150 & -0.031 & -0.049 & -0.224 \\
6 & -0.137 & 0.139 & 0.021 & 0.045 & 0.071 & -0.073 \\
7 & 0.017 & 0.278 & -0.382 & 0.221 & 0.231 & 0.038 \\
8 & -0.074 & 0.010 & -0.315 & 0.207 & 0.240 & 0.018 \\
\hline${ }^{*} \mathrm{p}<.05 ;{ }^{* *} \mathrm{p}<.01$ & & & & &
\end{tabular}




\section{Discussion}

\section{Behavioral data}

As predicted, reading habits seemed to have no effect on the accuracy of answers in the microproposition and macroproposition conditions. This could be explained by the fact that those two levels of comprehension are more related to memory capacity than to reading frequency.

The prediction was different for the situation model. Because it corresponds to a superior level of comprehension, it seemed logical to presume that reading habits could influence it. In fact, the results show that there was a trend toward a positive correlation, but not a significant one, between reading habits and accuracy of answers in the younger group. A positive correlation means that participants with stronger reading habits produced more accurate answers. This supports the hypothesis, but the lack of significance does not allow to make any further claims.

In the older group, there was a significant negative correlation between reading habits and accuracy of answers in the situation model condition. Elderly participants who obtained the highest scores for reading habits had the most difficulty in that condition of the task. One explanation could be that people with better reading skills read faster and tend to skip some details of the text, leading them to miss some essential components for the comprehension of the situation model. But this is probably not the case, because the same effect should have been seen in the microproposition and macroproposition conditions. Another possibility is that there may have been a methodological problem. Because there was a time limit of $5000 \mathrm{~ms}$ to answer each probe, some of the participants were not able to answer all of them. 
In the younger group, the correlation between reading habits and reaction times shows that the participants with better reading habits tended to answer faster (Figure 3). However, this correlation was not significant. In the elderly group, there was no significant correlation, or tendency, between reading habits and reaction times (Figure 4). This difference between the two age groups may be explained by the decline in processing speed in aging (Salthouse, 1996). This finding could suggest that better reading habits do not compensate for the decrease in processing speed with increased age. Further studies are needed to investigate the specific interaction between reading habits throughout life and the age-related decrease in processing speed.

\section{Neuroimaging data}

The hypothesis was that cerebral activity should be reduced in participants with stronger reading habits because the task should be easier for them. For the younger group, there was only one significant correlation between activity in the prefrontal cortex $(\mathrm{O} 2 \mathrm{Hb})$ and reading habits: in channel 5 for the situation model during the story reading. There was no significant correlation between activity in the prefrontal cortex and reading habits when we examined the variation in $\mathrm{HHb}$ concentration. Consequently, it is impossible to determine an effect of reading habits or observe a clear pattern in the younger group. Those results are not surprising if reading habits are considered as contributing to cognitive reserve (Stern, 2009). In that case, reading habits would help to slow or compensate for the cognitive decline linked to aging. Because this group was too young to show this kind of cognitive decline, their reading habits could not yet have a noticeable impact on cerebral activity. 
The results were more interesting for the older group. In fact, all the significant correlations between the variation in $\mathrm{O} 2 \mathrm{Hb}$ concentration and reading habits, except one, were in channels 5 and 7. Correlations can be observed for the microproposition probes and for story reading and the macroproposition and situation model probes. Those two channels are located next to each other in the left dorsolateral prefrontal area of the brain. So there is a relation between activity in those brain areas and reading habits. The fact that those correlations are found only in the left hemisphere is probably due to this hemisphere's dominance for language functions. The variation in the $\mathrm{O} 2 \mathrm{Hb}$ concentration was not the same during story reading and while answering the probes. In fact, when reading habits are strong, the brain activity measure in channels 5 and 7 is high for story reading and low for probe answering. Those results show that the more experienced readers made a greater effort in processing the story, maybe to make sure they got the maximum information from it. After that, they needed less of an effort to retrieve the information and answer the probes than those who had less reading experience.

A possible explanation of these results in the more frequent elderly readers is that cognitive decline, especially less efficient shortterm and working memory, leads the aging brain to make a greater effort to successfully maintain all the information needed. The participants who read less had not trained their brains for this kind of task, so their brains may not have been ready for the additional effort required to get and maintain all of the necessary information, which explains why they needed to make a greater effort to retrieve information and answer the probe questions. This explanation is also compatible with the absence of differences in the younger group, given that there was no need for compensation in that group. These results are in accordance with the cognitive reserve theory (Stern, 
2009). From that point of view, good reading habits help to increase a participant's cognitive reserves.

A study by Fincham and Anderson (2006) carefully examined the role of the left dorsolateral prefrontal cortex, especially Brodmann's area $9 / 46$, which corresponds to channel 7 in the present study. According to those authors, this area of the left hemisphere reflects memory retrieval demand. Their study shows a decrease in activity in the left dorsolateral prefrontal cortex region after training in a memory task. They attributed this decrease to the increased efficiency of the retrieval process. Another study observed a decrease in activity in the dorsolateral prefrontal cortex, in both hemispheres, after a period of training in a spatial stimulus-response task (Iacoboni, Woods, \& Mazziotta, 1996).

The present study shows a similar decrease in activation in the left dorsolateral prefrontal cortex region when the more experienced readers were answering the probes. This probably occurred mainly because of their increased efficiency at retrieving the required information. Unlike the study by Fincham and Anderson (2006), our participants had not practiced the task, but they had stronger reading habits. Thus, the participants had more experience in the same domain as the task, even though they had not received conscious training in it. This result shows the importance of life habits for brain plasticity.

While the results concerning $\mathrm{O} 2 \mathrm{Hb}$ concentration show the effects of reading habits circumscribed in only one area in the prefrontal cortex of the left hemisphere, the results concerning $\mathrm{HHb}$ concentration show no clear effects of reading habits on a particular area of the prefrontal cortex. In fact, a few significant Pearson's correlation coefficients between the variation in $\mathrm{HHb}$ concentration and reading habits were found, but they did not reflect a clear pattern, as was the case for $\mathrm{O} 2 \mathrm{Hb}$. 


\section{Conclusion}

This study investigated the interaction between reading habits and brain activity in a discourse comprehension task. The results provide some clues for formulating hypotheses about the effect of reading habits on the plasticity of the aging brain. The study shows the importance of the left dorsolateral prefrontal cortex in information retrieval. Further investigations are needed to reproduce and corroborate the results (especially concerning microproposition processing) and clarify hypotheses. Reading habits may have an effect on global cognitive reserve or maybe only on the cognitive aspects linked to language function. Future studies should include life habits questionnaires to isolate the effect of reading habits on cognitive reserve.

\section{References}

Buschke, H. (1973). Selective reminding for analysis of memory and learning. Journal of Verbal Learning and Verbal Behavior, 12, 543-550.

Cabeza, R. (2002). Hemispheric asymmetry reduction in older adults: The HAROLD model. Psychology and Aging, 17, 85-100.

Cao, Y., Vikingstad, E. M., George, K. P., Johnson, A. F., \& Welch, K. M. (1999). Cortical language activation in stroke patients recovering from aphasia with functional MRI. Stroke, 30, 2331-2340.

Chesneau, S. (2007). Effets du vieillissement et d'une lésion cérébrale gauche sur la compréhension de textes. Ph.D. dissertation, Département de sciences biomédicales, Faculté de médecine, Université de Montréal.

Chesneau, S., Jbabdi, S., Champagne-Lavau, M., Giroux, F., \& Ska, B. (2007). [Text comprehension, cognitive resources and aging]. Psychologie et Neuropsychiatrie du Vieillissement, 5, 47-64. 
Craik, F. I. M., \& Salthouse, T. A. (2000). The handbook of aging and cognition. Hillsdale, NJ: Lawrence Erlbaum Associates.

Davis, S. W., Dennis, N. A., Daselaar, S. M., Fleck, M. S., \& Cabeza, R. (2008). Que PASA? The posterior-anterior shift in aging. Cerebral Cortex, 18, 1201-1209.

Ericsson, K. A., \& Kintsch, W. (1995). Long-term working memory. Psychological Review, 102, 211-245.

Esteve, M. E., \& Gil, A. C. (2012). [Reading as a protective factor against cognitive decline.]. Gaceta Sanitaria [e-publication].

Fincham, J. M., \& Anderson, J. R. (2006). Distinct roles of the anterior cingulate and prefrontal cortex in the acquisition and performance of a cognitive skill. Proceedings of the National Academy of Sciences of the United States of America, 103, 12941-12946.

Folstein, M. F., Folstein, S. E., \& McHugh, P. R. (1975). Mini Mental State. Journal of Psychiatric Research, 12, 189-198.

Gratton, G., \& Fabiani, M. (2007). Optical imaging of brain function. In R. Parasuraman \& M. Rizzo (Eds.), Neuroergonomics: The brain at work (pp. 65-81). Oxford, UK: Oxford University Press.

Hoshi, Y. (2007). Functional near-infrared spectroscopy: Current status and future prospects. Journal of Biomedical Optics, 12, 062106.

Iacoboni, M., Woods, R. P., \& Mazziotta, J. C. (1996). Brain-behavior relationships: Evidence from practice effects in spatial stimulusresponse compatibility. Journal of Neurophysiology, 76, 321-331.

Jasper, H. (1958). Progress and problems in brain research. Journal of the Mount Sinai Hospital, New York, 25, 244-253.

Jones, R. N., Fong, T. G., Metzger, E., Tulebaev, S., Yang, F. M., Alsop, D. C., et al. (2010). Aging, brain disease, and reserve: Implications for delirium. American Journal of Geriatric Psychiatry, 18, 117-127.

Kelly, A. M., \& Garavan, H. (2005). Human functional neuroimaging of brain changes associated with practice. Cerebral Cortex, 15, 1089-1102.

Kintsch, W. (1988). The role of knowledge in discourse comprehension: A construction-integration model. Psychological Review, 95, 163-182. 
Kintsch, W., \& van Dijk, T. A. (1978). Toward a model of text comprehension and production. Psychological Review, 85, 363-394.

Lemaire, P., \& Bherer, L. (2005). Pyschologie du vieillissement. Uneperspective cognitive. Brussels: de Boeck.

Nelson, H. E. (1976). A modified card sorting test sensitive to frontal lobe defects. Cortex, 12(4), 313-324.

Oldfield, R. C. (1971). The assessment and analysis of handedness: The Edinburgh inventory. Neuropsychologia, 9, 97-113.

Parente, M. A. M. P., Fonseca, R. P., \& Scherer, L. C. (2008). Literacy as a determining factor for brain organization: From Lecours' contribution to the present day. Dementia e Neuropsychologia, 2, 165-172.

Park, D. C., \& Reuter-Lorenz, P. (2009). The adaptive brain: Aging and neurocognitive scaffolding. Annual Review of Psychology, 60, 173-196.

Radvansky, G. A. (1999). Memory retrieval and suppression: The inhibition of situation models. Journal of Experimental Psychology: General, 128, 563-579.

Radvansky, G. A., \& Dijkstra, K. (2007). Aging and situation model processing. Psychonomic Bulletin and Review, 14, 1027-1042.

Radvansky, G. A., Zwaan, R. A., Curiel, J. M., \& Copeland, D. E. (2001). Situation models and aging. Psychology and Aging, 16, 145-160.

Reitan, R. M., \& Wolfson, D. (1985). The Halstead-Reitan Neuropsychological Test Battery. Tucson: Neuropsychology Press.

Salthouse, T. A. (1996). The processing-speed theory of adult age differences in cognition. Psychological Review, 103, 403-428.

Schaie, K. W. (2008). Historical processes and patterns of cognitive aging. In S. M. Hofer \& D. F. Alwin (Eds.), Handbook on cognitive aging (pp. 368-383). Thousand Oaks, CA: Sage.

Scherer, L. C., Ska, B., Giroux, F., Lesage, F., Senhadji, N., Marcotte, K., et al. (2007). Discourse comprehension in successful aging: A NIRS study. Brain and Language, 103, 228-229.

Sole-Padulles, C., Bartres-Faz, D., Junque, C., Vendrell, P., Rami, L., Clemente, I. C., et al. (2009). Brain structure and function related to 
cognitive reserve variables in normal aging, mild cognitive impairment and Alzheimer's disease. Neurobiology of Aging, 30, 1114-1124.

Stern, Y. (2002). What is cognitive reserve? Theory and research application of the reserve concept. Journal of the International Neuropsychological Society, 8, 448-460.

Stern, Y. (2009). Cognitive reserve. Neuropsychologia, 47, 2015-2028.

Strangman, G., Boas, D. A., \& Sutton, G. P. (2002). Non-invasive neuroimaging using near-infrared light. Biological Psychiatry, 52, 679693.

Stroop, J. R. (1935). Studies of interference on serial verbal reaction. Journal of Experimental Psychology, 18, 643-662.

Van Dijk, T. A., \& Kintsch, W. (1983). Strategies of discourse comprehension. New York: Academic Press.

Wecksler, D. (1991). Échelle clinique de Mémoire de Wecksler-Révisée. Montréal: Centre de Psychologie appliquée.

Wilson, R., Barnes, L., \& Bennett, D. (2003). Assessment of lifetime participation in cognitively stimulating activities. Journal of Clinical and Experimental Neuropsychology, 25, 634-642.

Wolinsky, F. D., Mahncke, H., Vander Weg, M. W., Martin, R., Unverzagt, F. W., Ball, K. K., et al. (2010). Speed of processing training protects selfrated health in older adults: Enduring effects observed in the multi-site ACTIVE randomized controlled trial. International Psychogeriatrics, 22, 470-478.

[Received in October 8th, 2011. Approved in April 12th, 2012] 
